\title{
SECOND SASKATCHEWAN SPECIMEN OF POMARINE JAEGER
}

MERVYN SYROTEUK, Park Naturalist, Prince Albert National Park, Waskesiu Lake, Saskatchewan SOJ 2 Y0

On December 30, 1976, the staff of Prince Albert National Park held a bird observation day. First, a Cooper's Hawk was sighted along the Cookson Road, truly a fortunate chance that the vehicle speed and position should coincide so perfectly with the Cooper's inclination to fly by.

Chance intervened once more - a large dark bird was sighted on the road allowance at the Spruce River-highway 263 Junction, 15 miles south of Waskesiu Lake. The bird was alive but obviously in trouble. It managed to fly a few yards before landing on the snow again where it was surrounded and captured.

It had the appearance of a very dark immature gull, except that its legs were a startling light blue and were thinner than those of a gull. Its bill had a prominent hook. Dr. Stuart Houston met us in Prince Albert but his keys failed to identify the bird with certainty. Consultation with further books the next day indicated that it was too large for a Long-tailed Jaeger, too small for a Pomarine Jaeger and its legs were too blue for a Parasitic Jaeger.

Despite efforts to feed the thin jaeger, it died during the early morning of January 1 . It was frozen and shipped to the Museum of Natural Sciences in Ottawa, where it was identified as an immature Pomarine Jaeger, by Henri Ouellet. The specimen was a female, weighing only $356.9 \mathrm{~g}$, with a wing chord of only $326 \mathrm{~mm}$, and a culmen of only $35.6 \mathrm{~mm}$, measurements well below those given by Ridgway's keys. ${ }^{4}$

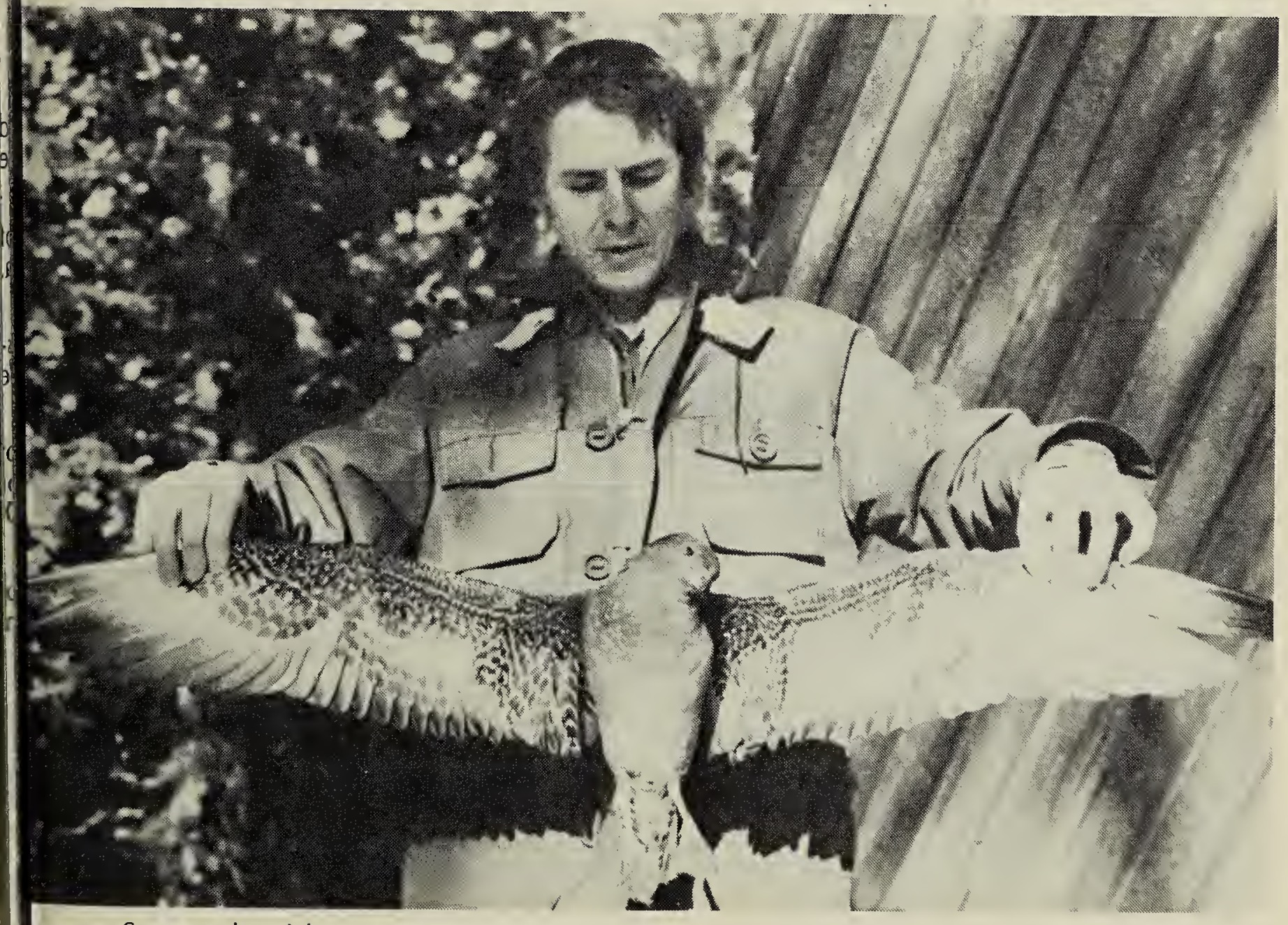

ervyn Syroteuk with Pomarine Jaeger 
This is the second specimen record for Saskatchewan for the Pomarine Jaeger; the first from Yellow Grass on November 9, 1922, ${ }^{2}$. There are also sight records from Kazan Lake by T. E. Randall and from Torch River by $C$. Stuart Francis. ${ }^{3}{ }^{1}$.

'FRANCIS, C. S. 1946. A list of the birds of Nipawin, Saskatchewan. Mimeographed July, 1943. Blue Jay 4:45.
${ }^{2}$ MITCHELL, H. H. 1924. Birds of Saskatchewan. Canadian Field-Nat. 38:101. 118.

${ }^{3}$ RANDALL, T. E. 1962. Birds of the Kazan Lake region, Saskatchewan. Blue Jay 20:60-72.

${ }^{4}$ RIDGWAY, ROBERT. 1919. The birds o North and Middle America: A de. scriptive catalogue. Vol. 8 Gov't. Print ing office Washington, D.C. 852 pp.

\section{WHITE RING-BILLED GULL AT SASKATOON}

\section{J. B. GOLLOP, 2202 York Avenue, Saskatoon, Saskatchewan S7J 1J1}

On July 14, 1977, R. C. Godwin reported a white gull on the lawn west of the Prairie Migratory Bird Research Centre, University Campus, Saskatoon. The bird was later studied with binoculars and photographed at distances of 50 to 150 meters for about 35 minutes by John Hanbidge and the author.

Most of the time, the plumage appeared to be pure white, even through binoculars, but at the right angle in full sun the back and wings were a very pale blue. The bill and legs were the same yellowish colour as nearby normal Ring-bills but the ring on the bill was washed out - a pale gray. The eye appeared dark. The wing tips and upper tail were white a observed when the bird was walkin and flying. The bill, head and bod appeared to be the same size as the smallest normal Ring-bill but wer noticeably smaller than four othe adults.

While the bird fed like other gulls it usually stayed away from the nor mally plumaged birds. It flew off $b$ itself about 0530 .

What was apparently the same bir was on the same lawn with up to 19 Ring-billed Gulls on August 4, 31 an September 1 (the date of writing).

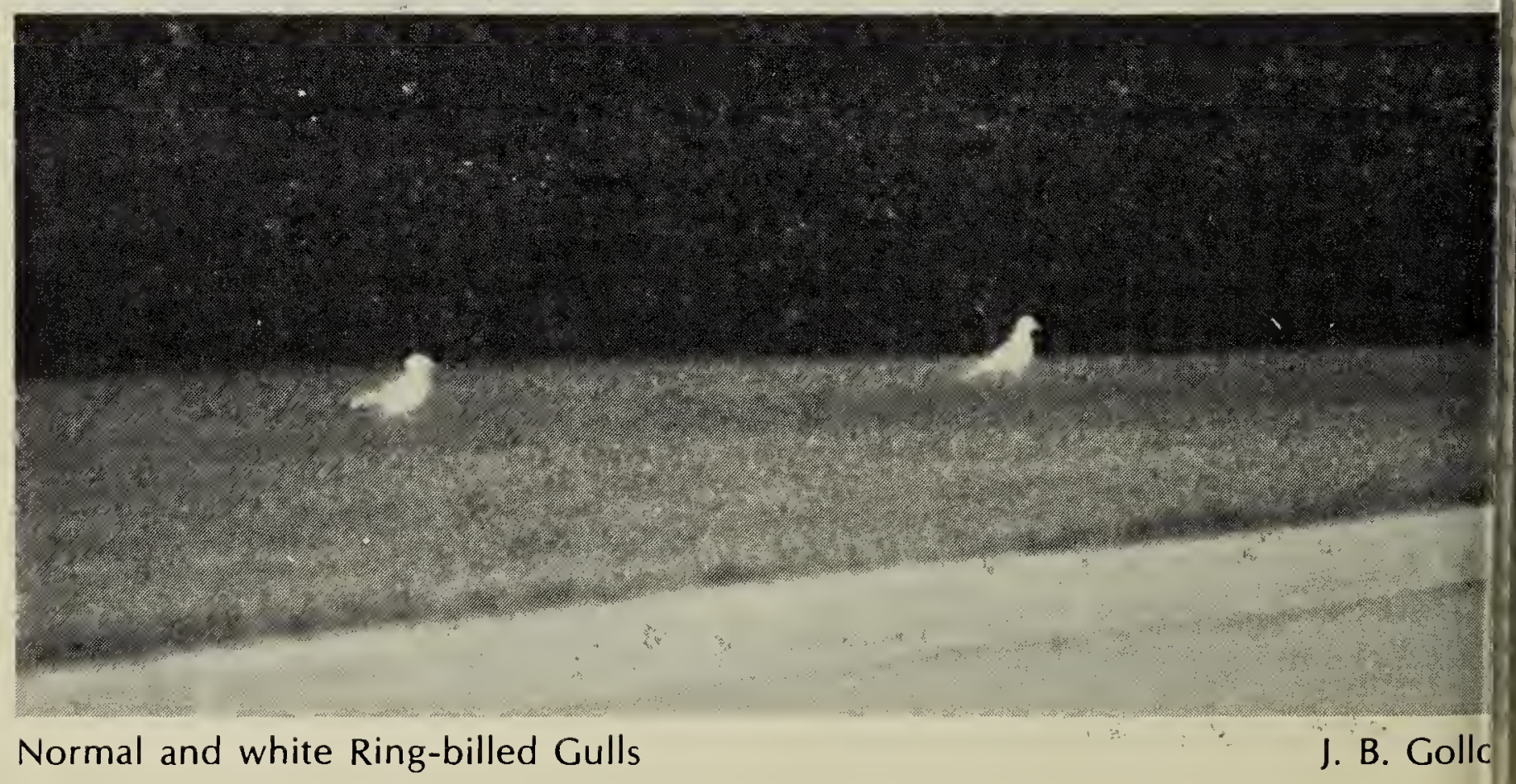

